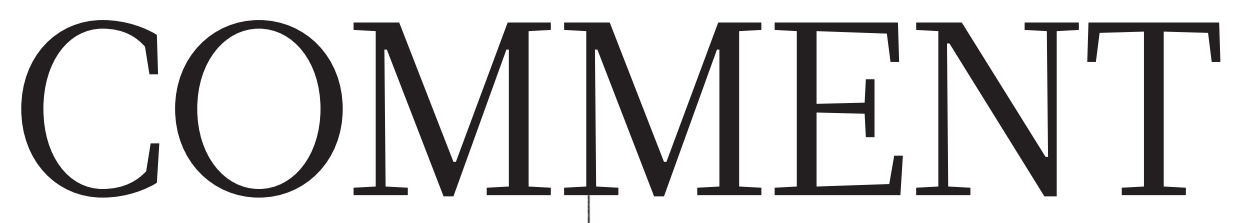

MACHINE LEARNING Three ways researchers must make algorithms more fair p.324
SUMMER BOOKS Survey of health inequities in African Americans p.328
13 hOLIDAY READING Luminous novel nails post-doc woes with gallows humour $\mathbf{p . 3 2 9}$
IRAN Trump will not crush scientists who have withstood decades of sanctions p.331

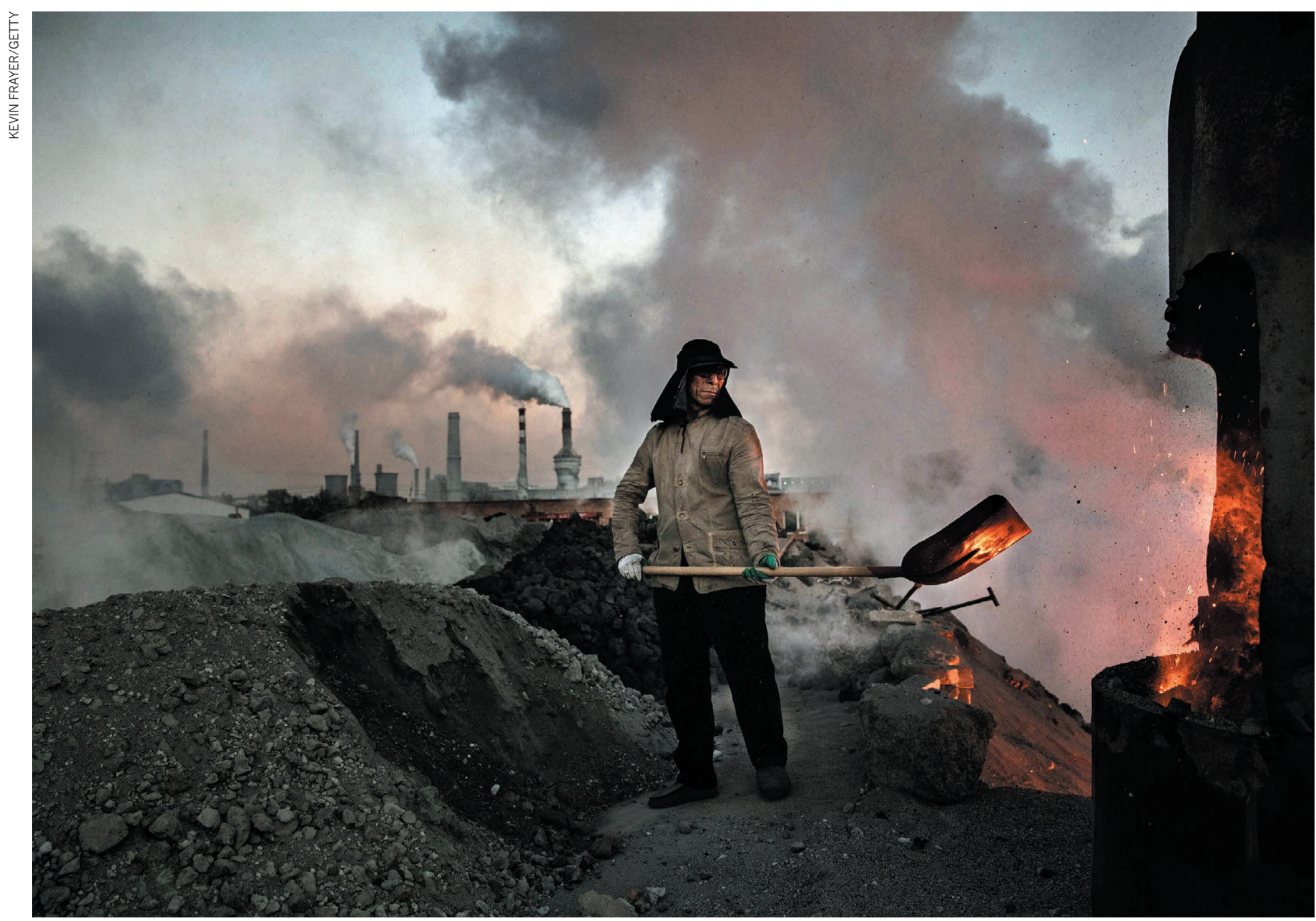

China is clamping down on unauthorized coal-fired factories, such as this one, to reduce carbon emissions.

\title{
Beat protectionism and emissions at a stroke
}

\section{Applying carbon charges, not trade tariffs, to imports would bolster the Paris Agreement, argue Michael Mehling and colleagues.}

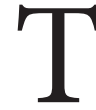

Two huge multilateral issues - free trade and climate change - top policymakers' agendas in 2018. This offers a chance to couple them.

More and more countries are shielding domestic producers from foreign competition
- a process known as protectionism. Since January, US President Donald Trump has slapped tariffs of up to $50 \%$ on many imports, including washing machines, solar cells, soya beans, steel and aluminium. Hopes that allied countries would be exempt were dashed after a tumultuous G7 meeting in June.

Economies affected have begun to respond in kind. China hit back with levies on US\$34 billion worth of US goods. The European Union increased tariffs on jeans, motorbikes and bourbon imported from the United $>$ 
- States. And Trump has since threatened to add tariffs on another $\$ 200$ billion worth of Chinese goods. A trade war is unfolding.

Meanwhile, nations are reviewing the pledges they made to cut emissions as part of the 2015 Paris Agreement. Everyone knows that current pledges will not keep global warming below the 'safe' limit of $2{ }^{\circ} \mathrm{C}$ above preindustrial levels - even if all nations deliver on their promises. The question is how to strengthen actions so that emissions drop sharply once the Paris framework takes effect in 2020.

The Paris process has two main problems. First, the pledges are uneven. Countries that do little will benefit from hefty cuts made by others. In the ultimate free ride, the United States will withdraw from the Paris Agreement in 2020, leaving others to do more. Second, carbon emissions 'leak' across borders. A country can keep its budget low by buying carbon-intensive goods made elsewhere. Some regions, such as Western and Northern Europe, import a considerable share of high-emission goods, allowing them to emit less themselves (see 'Carbon balance').

Over the next two years, there will be a flurry of activities relating to trade and climate change. This is a perfect opportunity to tie together the two agendas.
Governments should levy a carbon charge on imports. These 'border carbon adjustments' (BCAs) would level the emissions playing field by imposing the same economic burden on domestic and external manufacturers. Producers would lose the incentive to manufacture goods in places with weaker carbon regulations. Trade partners would then prefer to manufacture and export lowcarbon products to avoid penalties.

Political interest in BCAs is growing. In 2017, French President Emmanuel Macron called them 'indispensable' for European climate leadership, and Canadian environment minister Catherine McKenna recommended closer scrutiny. Mexico included them in its Paris pledge. But there are fears of retaliation and some confusion over the legality of BCAs. Here's how nations could proceed.

\section{CLIMATE-SMART TRADE}

BCAs should be applied to imported goods in line with their carbon footprint (the total of all the emissions released during their manufacture). A country might impose a fee on imported steel if its carbon footprint is higher than that of domestic steel, for example. Alternatively, governments might require importers to purchase emission allowances in carbon markets. The
US House of Representatives backed such an approach when it passed the WaxmanMarkey Bill in 2009; however, the bill failed to reach a vote in the Senate.

California is the only jurisdiction to have introduced BCAs, in its energy market. Since 2013, electricity delivered into California from neighbouring states has been subject to the same carbon constraints as that generated domestically. This has stopped electricity suppliers from shifting power generation to states with lax climate policies.

So far, efforts to limit emissions leakage have been less efficient. Some countries, including Germany, offer regulatory relief or compensation payments to domestic emitters to persuade them not to relocate. But such measures have undermined their other climate policies. For example, when the EU handed out emissions-trading permits for free, it weakened incentives to curb emissions and produced windfall profits for some energy-hungry companies.

BCAs, by contrast, bolster climate policies. By restricting trade in carbonintensive goods, they accelerate decarbonization even in countries with weak regulation. They also appeal to policymakers, manufacturers, trade associations and

Turkish steel awaits processing

in the US state of Texas.

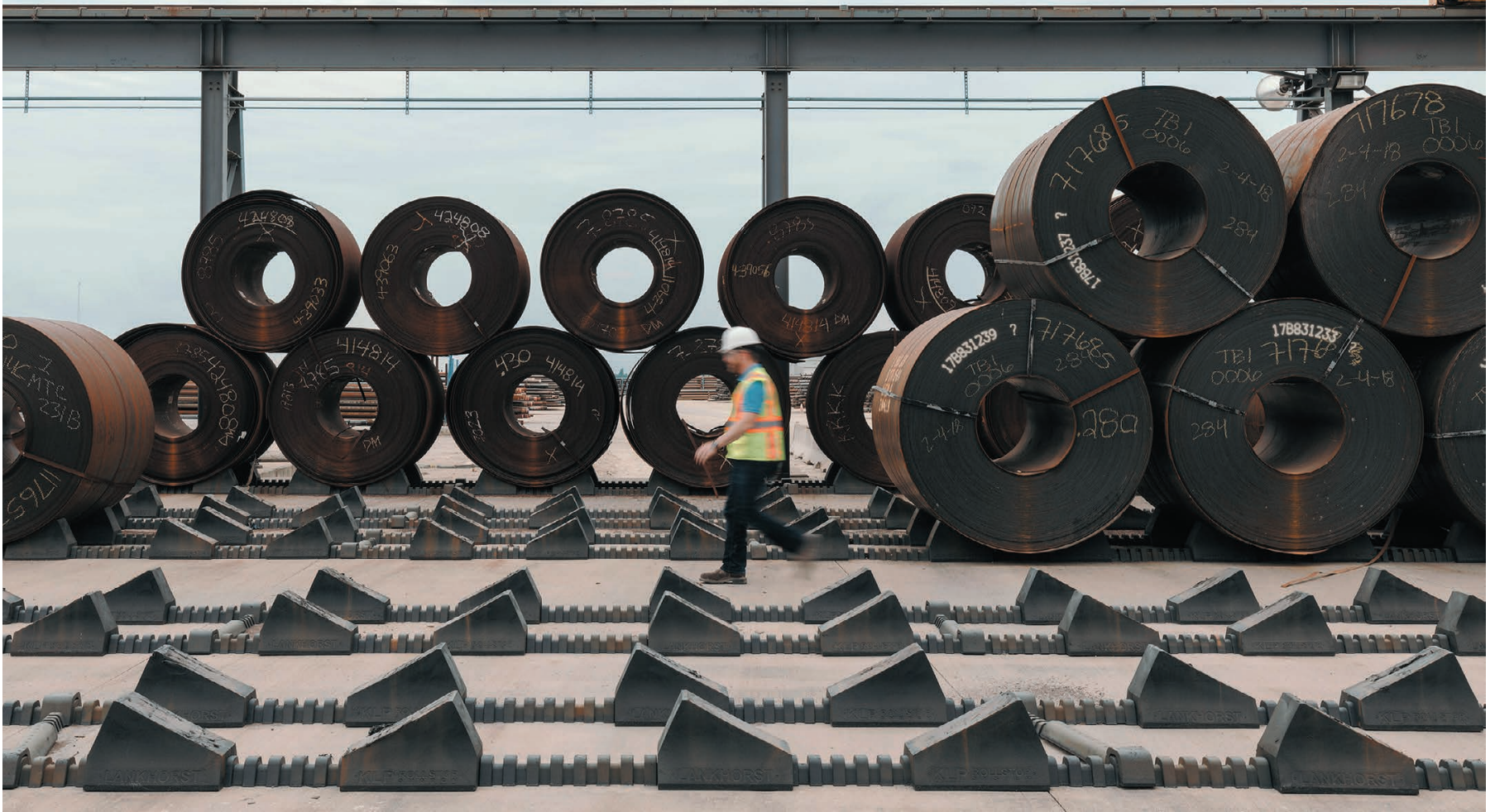




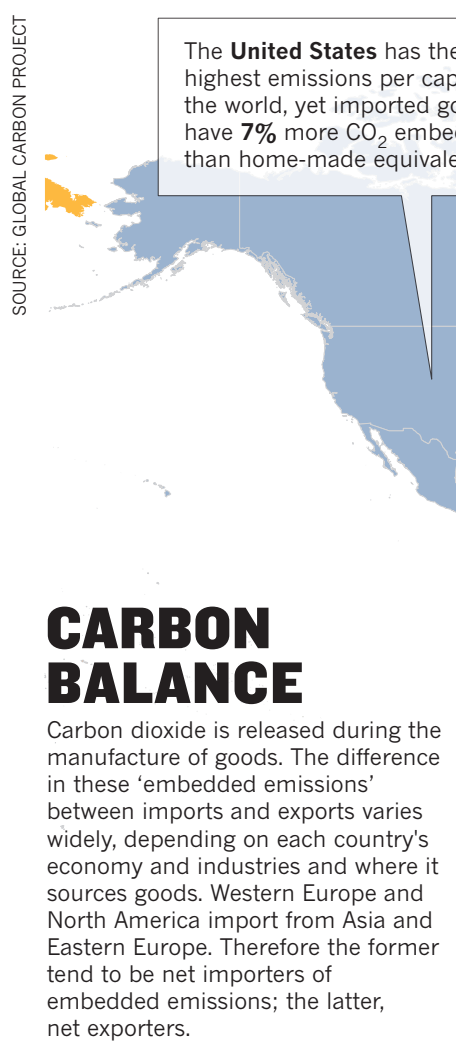

labour unions who are concerned about a nation's economy and jobs. Imposing BCAs on imports from the United States would prove politically popular with these groups. It would also strengthen the hand of progressive US states and cities that produce low-carbon goods. And it would get attention from targeted countries: US leadership has already shown that it is sensitive to trade measures, as evidenced by its quick reaction to retaliatory tariffs. Critics argue that BCAs are difficult to implement. They point to legal risks and the complexity of measuring carbon footprints.

\section{LEGALISSUES}

Some policymakers worry that BCAs violate a fundamental principle of the World Trade Organization (WTO): non-discrimination. This principle limits the ability of trade partners to adopt measures that distinguish between equivalent domestic and imported products. For example, it forbids regulators from applying a fee to imported cement unless the same fee applies to locally produced cement. That helps to avert protectionism. It also prevents countries from arbitrarily favouring one trade partner over another.

Because BCAs distinguish between products on the basis of their carbon footprint, they risk being considered discriminatory. For example, producers that make steel in open-hearth or blast-oxygen furnaces might incur a charge; those that produce the alloy in more-efficient electric-arc furnaces might not. Similarly, imposing BCAs on trade partners according to how much carbon they

produce could be seen as favouring some countries over others.

However, because BCAs aim to mitigate climate change, they would fall under a set of exceptions set out in WTO law. These justify measures "necessary to protect human, animal or plant life or health" or "relating to the conservation of exhaustible natural resources". To meet those criteria, BCA documentation must spell out the environmental goal, and the fees must be imposed through a transparent and fair pro-

\section{"Some of the United States' trade partners could forge a coalition."} cess. Using the revenue to fund mitigation and adaptation efforts, including in developing countries, would strengthen their environmental justification (M. Grubb, Clim. Policy 11, 1050-1057; 2011).

\section{NEXT STEPS}

BCAs should be introduced concurrently by a group of countries with the same goals. Some of the United States' trade partners could forge a coalition, including, for example, the EU, Canada and Mexico. Likewise, China has been strongly hit by US tariffs, and has expressed its intention to seek new alliances on climate and trade policy. Together, these nations have considerable economic clout - enough to secure US attention.

As a first step, these countries could base their response to US tariffs on the carbon intensity of goods. That alone would send a message about the importance of climate change.

As these countries advance increasingly ambitious climate policies, they should transition to a BCA that stands on independent footing from the current tariff conflict. The design of the programme must balance legal durability, ease of implementation and environmental performance. Below are our recommendations, based on a research project concluded last year (see go.nature.com $/ 2 \mathrm{kdhejm).}$

Determine scope and coverage. BCAs should target only countries that are not a party to the Paris Agreement. If the United States follows through with its announced withdrawal, its trade partners could impose a BCA. Periodic reviews of the adjustments should be tied to the global stocktaking process under the Paris Agreement. BCAs should be applied to a limited list of imported goods from sectors that emit a lot of carbon, such as iron, steel, aluminium, oil and gas refining, cement and lime, basic inorganic chemicals and pulp and paper. That would reduce the administrative burden, yet still realize many of the environmental benefits. In the United States, these sectors account for roughly half of all manufacturing emissions.

Calculate the footprint and set the adjustment. The carbon footprint should include direct emissions from production and indirect emissions from energy and heat inputs, and could be based on average benchmarks 
